\title{
Effect of Sexual Counseling on Marital Satisfaction of Pregnant Women Referring to Health Centers in Malayer (Iran): An educational randomized experimental study
}

\author{
Seyedeh Zahra Masoumi ${ }^{1}$, Farideh Kazemi ${ }^{2}$, Behnaz Nejati ${ }^{3}$, Parisa Parsa ${ }^{4}$, Manoochehr Karami ${ }^{5}$
}

${ }^{1}$ Ph.D. of Reproductive Health, Assistant Professor, Mother \& Child Care Research Center, School of Nursing and Midwifery, Hamadan University of Medical Sciences, Hamadan, Iran

${ }^{2}$ Ph.D. Candidate of Reproductive Health, Department of Midwifery \& Reproductive Health, School of Nursing \& Midwifery, Shahid Beheshti University of Medical Sciences, Tehran, Iran

${ }^{3}$ M.Sc. consultation in midwifery, Department of Midwifery, School of Nursing and Midwifery, Hamadan University of Medical Sciences, Hamadan, Iran

${ }^{4} \mathrm{Ph} . \mathrm{D}$. of Community Health, Associate Professor, Department of Mother and Child Health, School of Nursing \& Midwifery, Hamadan University of Medical Sciences, Hamadan, Iran

${ }^{5}$ Ph.D. of Epidemiology, Associate Professor, Social Determinants of Health Research Center, Hamadan University of Medical Sciences, Hamadan, Iran

\section{Type of article: Original}

\begin{abstract}
Introduction: One of the most important factors in marital satisfaction is the satisfaction of a healthy sexual relationship between spouses. During pregnancy marital satisfaction may decrease due to sexual problems. Sexual counseling to pregnant women may reduce the complications of these problems at this time. This study aimed to investigate the effects of sexual counseling on marital satisfaction of pregnant women. This article is sponsored by the Hamadan University of Medical Sciences.

Methods: This educational randomized experimental study was conducted on 80 pregnant women referring to health centers of Malayer. Samples were two groups of experimental and control, with forty participants in each group, four consultation sessions were held, and each session lasted 40 to 90 minutes Data gathering tools were demographic questionnaire and Enriching Relationship Issues Communication and Happiness (ENRICH), a short form of marital satisfaction questionnaire with 47 items. Data were analyzed by Software SPSS 22 and the results were compared by independent t-test, chi-square test, and repeated measure ANOVA.

Results: Comparing the marital satisfaction mean scores in the experimental group showed a significant difference between pre-consultation, and the consultation after two and four weeks. Marital satisfaction score of $8.05 \pm 51.20$ before the consultation was increased to $7.76 \pm 54.52$ after two weeks and $6.48 \pm 59.20$ after four weeks (respectively $\mathrm{p}<0.001, \mathrm{p}<0.001$ ). In addition, mean and standard deviation of marital satisfaction in the control group before the intervention, two weeks and four weeks after the intervention were respectively $10.10 \pm$ 45.67, $11.75 \pm 47.75$, and $10.02 \pm 46.30$ and Bonferroni post hoc test showed a significant difference between before and two weeks after intervention $(\mathrm{p}=0.03)$. However, marital satisfaction before and four weeks after the intervention was not significant $(\mathrm{p}=0.59)$. The results showed that sexual counseling was associated with marital satisfaction and was effective in its promotion.

Conclusion: Sexual counseling can be used as a method of intervention in sexual relationship of spouses particularly in marital dissatisfaction.

Keywords: Marital satisfaction, Sexual satisfaction, Sexual counseling, Pregnancy
\end{abstract}

\section{Corresponding author:}

Behnaz Nejati, Department of Midwifery, School of Nursing and Midwifery, Hamadan University of Medical Sciences, Hamadan, Iran. Tel: +98. 9183540109, Fax: +98. 8138380447-081, Email: behnaznejati88@gmail.com Received: June 10, 2016, Accepted: August 26, 2016, Published: January 2017

iThenticate screening: August 26, 2016, English editing: November 27, 2016, Quality control: December 20, 2016 (C) 2017 The Authors. This is an open access article under the terms of the Creative Commons Attribution-NonCommercialNoDerivs License, which permits use and distribution in any medium, provided the original work is properly cited, the use is non-commercial and no modifications or adaptations are made. 


\section{Introduction}

Marital relationship is described as the most important and most fundamental human relationship because it provides the basic structure for building family relationship and training the next generation (1). To Silliman, marital satisfaction is a condition in which couples often have feelings of happiness and satisfaction from each other and from their marriage. One of the best definitions of marital satisfaction is provided by Hawkins; He defined marital satisfaction as a visual feeling of happiness, satisfaction, and joy experienced by a husband and wife who considered all aspects of their marriage $(2,3)$. Satisfaction is an attitude and is considered as a personal attribute of a couple (4). Satisfactory marital relationships grow competence and an ability to adapt and compromise in people and these people generally have a longer life,, and have lower depression and psychological disorders and their children are more adaptable, and have better academic achievements (5). Sexual satisfaction is important for most couples and is considered as a personal matter. Sexual relationship satisfaction is one of the important factors of marital satisfaction that affects health and quality of a couple's life (6). If the sexual relationship between couples is not convincing it can lead to frustration, deprivation, lack of security, and reduction of mental health, and as a result, decrease of marital satisfaction and family disintegration $(7,8)$. On the other hand, sexual relationships form an important part of a couple's perceptions of each other which maintains their marriage (9). Definition of sexual satisfaction refers to judgment and analysis of each individual of his sexual behavior, based on enjoyment. A high level of sexual satisfaction leads to higher marital quality and this leads to a decreased instability in marital life $(10,11)$. Satisfaction of the sexual relationship is one of the important factors of marital satisfaction and those who have more sexual satisfaction report a significantly better quality of life than those who do not have sexual satisfaction $(11,12)$. In studies, there was a direct link between sexual satisfaction and marital satisfaction, in a way that more sexual satisfaction followed more marital satisfaction (12-14). Based on the results reported in Iran, many couples suffer from lack of satisfaction with sexual relationships and 50 to 60 percent of divorce cases and 40 percent of betrayals and hidden associations are for this reason (15-18). Couples' inadequate information about sexual relationships during pregnancy and negative attitudes and superstitions towards these relationships in this period, cause problems and a reduction in sexual relationship, or discontinuation without reason. This can cause the loss of an emotional and loving relationship from the husband's side and anxiety and lack of confidence in mothers (19-21). This causes confusion and controversy at a time when couples need more than ever to be close together (22). Cole says marital counseling teaches couples how to empathize with their spouses in critical condition and minimize misinterpretations and improve marital satisfaction (23). Sexual counseling is a long process by which people acquire information and knowledge about their sexual issues and constitute attitudes, beliefs, and their values. It is a process that helps healthy sexual development, marital health, interpersonal relationships, affection, closeness, body image, and gender roles (24). Counseling and educational programs about sexual health can improve sexual satisfaction and thus increase the quality of marital life (25). Midwifery counseling prevents psychosexual impairments through the provision of information, advice, and awareness, and helps couples to understand the problem, review, and analyze it and decide and choose the right solution (26). Given that few studies have been carried out in support of the impact of sexual counseling on pregnant women's marital satisfaction, this study aimed to investigate the effect of sexual counseling on pregnant women's marital satisfaction.

\section{Material and Methods}

\subsection{Research design and participants}

This study was an educational randomized experiment with a control group that was conducted in 2015 in Malayer. The study included 80 pregnant women (40 participants in experimental group and 40 in control group).

\subsection{Selection Criteria}

Inclusion criteria were gestational age 24-26 weeks, age range 18-35 years, passing of at least one year of marriage, absence of addiction, of wife and husband, to drugs and alcohol, absence of acute and debilitating mental disease of wife and husband, absence of sexual identity disorder of wife and husband, and absence of hypnotic drug usage. Exclusion criteria included any pregnancy problem during the study (abortion, placental abruption, fetal malpresentation, cord prolapse, bleeding, diabetes, hypertension, preterm birth, etc.), abnormal fetal heart rate patterns or reduced fetal movements that need to have medical intervention.

\subsection{Interventions}

First, all pregnant women who were in 24-26 weeks pregnancy and had required criteria were included and then were assigned randomly into two groups. Initially, both groups before the intervention completed the Enrich marital satisfaction questionnaire. The control group in one month only received routine counseling from the midwife of the clinic while the experimental group enjoyed routine care as well as sexual counseling weekly by a trained midwife. 
Weekly meetings were held in four sessions of 45-90 minutes (Table 1). The researcher had a weekly phone call with them to review and strengthen marital satisfaction in the experimental group. In the present study to measure marital satisfaction, the Enrich, a short form of marital satisfaction questionnaire with 47 items on marital satisfaction was used. The questionnaire was designed by Olsen et al. and used to determine the scope of work and the strength points of the marital relationship (27). The use of this questionnaire is also to identify couples who need counseling and strengthen their relationship. Keramat et al. have reported the validity of the questionnaire with alpha 0.91 (12). In this 47 questions form, scoring is based on a 5 grade scale (strongly agree, agree, neither agree nor disagree, disagree, strongly disagree). The maximum score of a subject is 100 and higher scores indicate more sexual satisfaction. A score below 30 indicates strong dissatisfaction of spouses, scores 30 to 40 indicate a lack of satisfaction with relationships, scores 40 and 60 indicate average satisfaction of spouses, scores between 60 to 70 marker high satisfaction, and scores higher than 70 indicate extreme satisfaction with marital relationships between spouses (28). For post-test both group completed the questionnaire 2 weeks and 4 weeks after completion of consultation and then the results were analyzed.

Table 1. Educational programs offered to the intervention group

\begin{tabular}{|l|c|l|}
\hline $\begin{array}{l}\text { Meetings } \\
\text { Number }\end{array}$ & The content of meetings (Time 90-45 minute consultations) \\
\hline First session & $\begin{array}{l}\text { Description and anatomy and physiology of the mother during pregnancy } \\
\text { Four stages of sexual response cycle's description of the physical and psychological } \\
\text { differences between men and women at each stage of the sexual cycle }\end{array}$ \\
\hline $\begin{array}{l}\text { Second } \\
\text { session }\end{array}$ & $\begin{array}{l}\text { Review and explain the domain of sexual function and its changes during pregnancy } \\
\text { Third session }\end{array}$ & $\begin{array}{l}\text { The pattern followed and sexual changes during pregnancy } \\
\text { Fourth } \\
\text { Session }\end{array}$ \\
& $\begin{array}{l}\text { Observing hygiene necessary during intercourse in pregnancy } \\
\text { Factors affecting sexual satisfaction and marital satisfaction followed in pregnancy }\end{array}$ \\
\hline
\end{tabular}

\subsection{Outcomes}

The primary outcome was studying the level and amount of marital satisfaction in both experimental and control groups two weeks after the intervention and the secondary outcome was studying that in the two groups after four weeks.

\subsection{Sample Size}

According to the study of Rostamkhani et al. (2002), by $\alpha=0.05, \beta=0.20$, the required number of samples was calculated as 80 people. Therefore, in this study 40 participants randomly assigned to the experimental group (receiving consultation) and 40 participants to the control group (without consultation).

\subsection{Randomization and Blinding}

Given that there are five urban centers in Malayer, 4 health centers were randomly selected of which two were allocated to the control group (health centers 1 and 3) and two to the experimental group (2 and 5). In each center 10 patients were studied. By random sampling and using computer and software SPSS the participants were selected. By this method, arbitrarily assigning subjects to experimental and control groups was prevented. And because the selection of participants was done in separate centers there was no need to blind.

\subsection{Statistical Methods}

Statistical analysis of data was done by software SPSS-16 (SPSS Inc., Chicago, Illinois, USA) and the results were compared by independent t-tests, chi-square test, and repeated measures ANOVA.

\subsection{Research Ethics}

The proposal for this thesis research was presented to the Ethics Committee of Hamadan University of Medical Sciences after its scientific approval by the midwifery department. The Ethics Committee approved the study on July 24, 2015 (Ref. no: IR.UMSHA.REC.1394.225). In addition, the participants were informed about the objective of the study, and each participant provided her written consent in her native language (Persian) prior to the study. Also, we were committed to keeping all of the participants' information confidential. In addition, participants could be excluded whenever they didn't want to participate in the study. 


\section{Results}

In the present study 80 pregnant women had the criteria and were evaluated in the experimental $(n=40)$ and control group $(n=40)$. Based on Kolmogorov-Smirnov test, the variables had a normal distribution $(p>0.05)$. In addition based on the Chi-square test there was no significant difference between the experimental and control group in any of the qualitative variables $(p>0.05)$. Therefore, pregnant women were the same in both groups. The t-test showed no significant difference between the experimental and control group in any of the quantitative variables $(\mathrm{p}>0.05)$. Therefore, the average of variables was similar in both groups. Based on the results of the qualitative variables, the results showed $15.0 \%$ were employed in the experimental and control groups. The most frequency in education levels of pregnant women was high school $42.5 \%$ (17 people), in 35\% of their spouses (14 people) was high school and in $35 \%$ (14 people) was university education. $77.5 \%$ (31 people) had wanted pregnancies. $90 \%$ ( 36 people) reported sexual satisfaction before pregnancy and $52.5 \%$ (21 people) were unaware of safe sex during pregnancy. The mean age of mothers in the experimental group was $26.32 \pm 3.92$ years and was $27.10 \pm 4.77$ years in the control group (Table 2). By repeated measures ANOVA, variables of marital satisfaction in three time periods of before, after, and four weeks after the intervention were compared in each experimental and control groups. Based on this test shown in Table 2, there was a significant difference among the average scores in three periods in the experimental group $(p<0.05)$. Therefore by using LSD method sexual satisfaction variables were compared two by two. The results in Table 3 showed significance differences among average scores of marital satisfaction in the experimental group before and two weeks after the intervention, before and four weeks after the intervention, and two weeks and four weeks after the intervention $(\mathrm{p}<0.05)$. Therefore, marital satisfaction scores were increased from $51.20 \pm 8.05$ before the intervention to $54.52 \pm 7.76$ in two weeks after and $59.20 \pm 6.48$ in four weeks after. The average and standard deviation of marital satisfaction in the control group before the intervention, two weeks, and four weeks after the intervention were $45.67 \pm 10.10,47.75 \pm 11.05$, and $46.30 \pm 10.02$ respectively. As it is shown in Table 3, in the experimental group four weeks after the intervention, the percentage of people who had great satisfaction was increased. It was also observed in the experimental group before the intervention most people $(75 \%)$ mentioned average satisfaction that in two weeks after the intervention was still the highest figures for average satisfaction (75\%). In addition, four weeks after the intervention, the majority of people cited average satisfaction (47.5\%). While in four weeks after the intervention, $2.5 \%$ were dissatisfied, $45 \%$ highly satisfied, and $5 \%$ extremely satisfied. The mean and standard deviation of marital satisfaction in the control group before the intervention, two weeks after, and four weeks after the intervention were $45.67 \pm 10.10,47.75 \pm 11.75$, and $46.30 \pm$ 10.02 respectively which based on the paired t-test there was a significant difference between before and two weeks after the intervention $(\mathrm{p}=0.03)$ but in marital satisfaction before and four weeks after the intervention there was no significant difference $(\mathrm{p}=0.59)$.

Table 2. Demographic characteristics and pregnancy in women referred to health centers in the experimental group and control Malayer city

\begin{tabular}{|l|l|l|l|l|l|}
\hline Profile of quantitative variables & \multicolumn{2}{l|}{ Study group } & Control group & \\
\cline { 2 - 6 } & Average & $\begin{array}{l}\text { Standard } \\
\text { deviation }\end{array}$ & Average & $\begin{array}{l}\text { Standard } \\
\text { deviation }\end{array}$ & $\begin{array}{l}\text { p- } \\
\text { value }\end{array}$ \\
\hline Age (years) & 26.32 & 3.92 & 27.10 & 4.77 & 0.43 \\
\hline Revenue (Rials)/ month & 12175000 & 1.15 & 9275000 & 4.96 & 0.14 \\
\hline Gestational age & 24.77 & 0.83 & 24.77 & 0.80 & 1.00 \\
\hline Parity & 1.62 & 0.70 & 1.97 & 1.04 & 0.08 \\
\hline The number of living children & 0.55 & 0.59 & 0.72 & 0.93 & 0.32 \\
\hline The abortion & 0.10 & 0.30 & 0.30 & 0.60 & 0.06 \\
\hline $\begin{array}{l}\text { The number of children who have } \\
\text { died }\end{array}$ & 0.05 & 0.22 & 0.00 & 0.00 & 0.16 \\
\hline
\end{tabular}


Table 3. Compare the relative frequency distribution of marital satisfaction test and control groups

\begin{tabular}{|l|l|l|l|l|l|l|}
\hline \multirow{2}{*}{ Variable } & \multicolumn{2}{|l|}{ Study group } & \multicolumn{2}{l|}{ Control group } \\
\cline { 2 - 7 } & $\begin{array}{l}\text { Before } \\
\text { intervention }\end{array}$ & $\begin{array}{l}2 \text { weeks } \\
\text { after } \\
\text { intervention }\end{array}$ & $\begin{array}{l}\text { 4 weeks after } \\
\text { intervention }\end{array}$ & $\begin{array}{l}\text { Before } \\
\text { intervention }\end{array}$ & $\begin{array}{l}\text { 2 weeks after } \\
\text { intervention }\end{array}$ & $\begin{array}{l}\text { 4 weeks after } \\
\text { intervention }\end{array}$ \\
\cline { 2 - 7 } & $\begin{array}{l}\text { Abundance } \\
\text { Percent }\end{array}$ & $\begin{array}{l}\text { Abundance } \\
\text { Percent }\end{array}$ & $\begin{array}{l}\text { Abundance } \\
\text { Percent }\end{array}$ & $\begin{array}{l}\text { Abundance } \\
\text { Percent }\end{array}$ & $\begin{array}{l}\text { Abundance } \\
\text { Percent }\end{array}$ & $\begin{array}{l}\text { Abundance } \\
\text { Percent }\end{array}$ \\
\hline Dissatisfaction & $4(10.0)$ & $2(5.0)$ & $1(2.5)$ & $10(25.0)$ & $12(30.0)$ & $13(32.5)$ \\
\hline $\begin{array}{l}\text { Average } \\
\text { satisfaction }\end{array}$ & $30(75.0)$ & $30(75.0)$ & $19(47.5)$ & $25(62.5)$ & $21(52.5)$ & $22(55.0)$ \\
\hline $\begin{array}{l}\text { High } \\
\text { satisfaction }\end{array}$ & $5(12.5)$ & $7(17.5)$ & $18(45.0)$ & $3(7.5)$ & $6(15.0)$ & $5(12.5)$ \\
\hline $\begin{array}{l}\text { Extreme } \\
\text { satisfaction }\end{array}$ & $1(2.5)$ & $1(2.5)$ & $2(5.0)$ & $2(5.0)$ & $1(2.5)$ & $0(0.0)$ \\
\hline
\end{tabular}

\section{Discussion}

Based on the results, the marital satisfaction score in the experimental group before the intervention was $51.20 \pm$ 8.05 , and increased after two weeks to $54.52 \pm 7.76$, and after four weeks to $59.20 \pm 6.48$ in two weeks, four weeks after the intervention increased, and there was a significant difference in this group $(\mathrm{p}<0.001, \mathrm{p}<0.001$ respectively). The results of the present study is consistent with the study of Mangeoli et al. which was intervention by introducing an educational pamphlet and marital satisfaction scores were collected before and one month after that intervention. Because marital satisfaction scoring was increased from $168.8 \pm 28$ before training to $187.3 \pm 18.2$ after training they concluded that by providing training on features and changes during pregnancy and after childbirth, marital satisfaction can be increased. The study is also consistent with the study of Schulz and Zimmermann on the effectiveness of counseling on sexual and marital satisfaction (29-31). The present study is also consistent with the study of Pakgohar et al. which was about sexual counseling for infertile women in two stages, before and three months after (8). Baron and Byrne in their studies suggested that sex education or marital counseling plays an important role in family health, reducing sexual violence in the family, prevention of sexually transmitted diseases, positive attitude towards sexual relations, sexual pleasure, reducing conflict in the family, gaining experience of sexual pleasure and sexual satisfaction, and as a result marital satisfaction (32). Rahnama in 2002 with the short form questionnaire of Enrich evaluated marital satisfaction of spouses before and after training, and announced the positive effect of training (33). Avery also showed that after counseling, post-test score which was six months later, was far above the pre-test score. The results of present study are similar to the above mentioned findings and suggest that sexual counseling increases sexual satisfaction; therefore, the statistical test showed significant differences in each stage compared to previous stages $(\mathrm{p}<0.001)$. Jahanfar et al. believes that by providing appropriate advice on sexual problems, they will be disappeared in spouses' relationships gradually, and unawareness will be replaced by full knowledge (34). The present study showed lack of sexual counseling, and intervention in the control group didn't make any changes in increase of mean and standard deviation of the people and therefore statistical test showed no significant differences in each stage than the previous one (two and four weeks, respectively, compared to pre-intervention, $\mathrm{p}=0.034, \mathrm{p}=0.593$ ). The present research is consistent with the study of Babazadeh et al. titled The Investigation of Teaching Impact on Changes of Sexual Activity During Pregnancy, and no significant difference was observed between sexual satisfaction of women in the control group before and two months later $(\mathrm{p}=0.83)$. However, in sexual satisfaction of women in the intervention group, a significant difference was seen before and two months after the training (35). In the present study, by comparing the experimental and control groups, we came to conclusion that there was a significant difference between the experimental and control groups after intervention which is consistent with the study of Pakgohar et al. (8), and by doing intervention the marital satisfaction was more increased in the experimental group than in the control group, and this difference was statistically significant $(\mathrm{p}<0.001)$. The present study is consistent with the study of Cooper et al. This study compared a program to improve sexual relations on sexual and marital satisfaction. Couples in the experimental group, for four consecutive weeks, participated in the training program two sessions in a week. A control group was also considered. All three groups were evaluated three months after the end of sessions, before, during, and after the training. The analysis of covariance showed that spouses who had participated in the program to improve sexual relations had more sexual satisfaction than two other groups and they also had more feelings of affection and reported considerably more marital satisfaction (36). Nouranipour showed that sexual skills training can cause positive emotions, closeness, and intimacy with your partner, enhancing marital relationships, and as the result its continuation, and increasing a couple's ability to resolve conflict and have marital satisfaction (37). Byers, 
who in his research looked for a causal relationship between sexual relations and marital relationships concluded that there is a mutual two-way interaction between sexual satisfaction and marital satisfaction (38). A study conducted by Corsini in 1953 concluded that sexual relationships form a part of couples' perceptions of each other that maintain marriage. His findings also showed that marital satisfaction can depend on conformance or compliance of couples in their sexual relations (9).

\section{Conclusions}

In summary, the findings of this study showed that sexual counseling during pregnancy could be effective in increasing marital satisfaction of pregnant women. Functional significance of these findings is that by providing advice regarding sexual matters of couples, they can be prepared to deal with changes of pregnancy periods and adapt to them and so the tensions and disputes of couples can be avoided. It is suggested that during pregnancy, mental health education and counseling for couples is conducted in health care centers. Conducting a complementary study on the impact of sexual counseling on sexual and marital satisfaction among pregnant women as a randomized clinical trial can be an appropriate path for future research in this field.

\section{Acknowledgments:}

This paper is the result of a thesis for M.A. in counseling in Hamadan University of Medical Sciences. The authors express their thanks and gratitude to all those who participated in the research and workers of health care centers in Malayer (number one, two, three, and five), especially Mrs. Doctor Golfam and Paraie.

\section{Conflict of Interest:}

There is no conflict of interest to be declared.

\section{Authors' contributions:}

All authors contributed to this project and article equally. All authors read and approved the final manuscript.

\section{References:}

1) Larson JH, Holman TB. Premarital predictors of marital quality and stability. Family Relations. 1994; 43(2): 228-37. doi: 10.2307/585327.

2) Silliman B, Schumm WR. Marriage preparation programs: A literature review. Fam J Alex Va. 2000; 8(2): 133-42. doi: 10.1177/1066480700082004.

3) Hawkins JL. Associations between companionship, hostility, and marital satisfaction. J Marriage Fam. 1968; 30(4): 647. doi: 10.2307/349510.

4) Aliakbari Dehkordi M. Relationship between women sexual function and marital adjustment. Journal of Behavioral Sciences. 2010; 4(3): 11-2.

5) Wagheiy $\mathrm{Y}$, Miri M, Ghasemipour M. A survey about effective factors on the marital satisfaction in employees of two Birjand universities. J. of Birjand University of Med. Sci. 2009; 16(4): 43-50.

6) Movahed M, Azizi T. A study on the relationship between the sexual satisfaction of women in a married life and conflicts between spouses, among married women in Shiraz. woman in development and politics. 2011; 9(2(33)): 191-216.

7) Mirghaforvand M, Alizadeh S, Asghari M, Tavananezhad N, Karkhaneh M. Individual-Social predictor of marital satisfaction in women of reproductive age in Tabriz. Iranian Journal of Obstetrics, Gynecology and Infertility. 2013; 16(72): 1-12.

8) Pakgohar M, Vizheh M, Babaee G, Ramezanzadeh F, Abedininia N. Effect of counseling on sexual satisfaction among infertile women referred to Tehran fertility center. Hayat. 2008; 14(1): 21-30.

9) Corsini RJ. Understanding and similarity in marriage. J Abnorm Soc Psychol. 1956; 52(3): 327-332. doi: 10.1037/h0043556.

10) Simons JS, Carey MP. Prevalence of sexual dysfunctions: Results from a decade of research. Arch Sex Behav. 2001; 30(2): 177-219. doi: 10.1023/A:1002729318254.

11) Young M, Denny G, Young T, Luquis R. Sexual satisfaction among married women age 50 and older. Psychol Rep. 2000; 86(3 Pt 2): 1107-22. doi: 10.2466/pr0.2000.86.3c.1107. PMID: 10932565.

12) Keramat A, Masoomi SZ, Mousavi SA, Poorolajal J, Shobeiri F, Hazavhei SM. Quality of life and its related factors in infertile couples. J Res Health Sci. 2014; 14(1): 57-63. PMID: 24402852.

13) Brezsnyak M, Whisman MA. Sexual desire and relationship functioning: the effects of marital satisfaction and power. J Sex Marital Ther. 2004; 30(3): 199-217. doi: 10.1080/00926230490262393. PMID: 15205075 . 
14) Guo B, Huang J. Marital and sexual satisfaction in Chinese families: exploring the moderating effects. J Sex Marital Ther. 2005; 31(1): 21-9. doi: 10.1080/00926230590475224. PMID: 15841703.

15) Rahmani A, Safavi SH, Jafarpoor M, Merghati Khoei E, Hosseini Agha F. The relation of sexual satisfaction and demographic factors. Iran Journal of Nursing. 2010; 23(66): 14-22.

16) Rahnama A. Effects of marriage on marital satisfaction of a group of couples covered by Imam Khomeini Relief Committee. Daneshvar. 2002; 10(43): 77-80.

17) Sharyati M, Ghamarani A, Solati Dehkordi S, Abbasi Molid H. The study of relationship between alexithymia and sexual satisfaction among female married students in Tabriz University. J Fam Res. 2010; 6(1): 59-70.

18) Shafiabadi A, Honarparvaran N, Tabrizi M, Navabinezhad S. Efficacy of emotion-focused couple therapy training with regard to increasing sexual satisfaction among, couples. Andisheh va Raftar. 2010; 4(15): 5970.

19) Bartellas E, Crane JM, Daley M, Bennett KA, Hutchens D. Sexuality and sexual activity in pregnancy. BJOG. 2000; 107(8): 964-8. doi: 10.1111/j.1471-0528.2000.tb10397.x. PMID: 10955426.

20) De Judicibus MA, McCabe MP. Psychological factors and the sexuality of pregnant and postpartum women. J Sex Res. 2002; 39(2): 94-103. doi: 10.1080/00224490209552128. PMID: 12476241.

21) Malarewicz A, Szymkiewicz J, Rogala J. [Sexuality of pregnant women]. Ginekol Pol. 2006; 77(9): 733-9. PMID: 17219804.

22) Moin Z. Mental health in pregnancy period. Tehran: Centeral Rehabilitation Organization. 2002.

23) Cole CL, Cole AL. Marriage enrichment and prevention really works: Interpersonal competence training to maintain and enhance relationships. Fam Relat. 1999; 48(3): 273-5. doi: 10.2307/585637.

24) Shams Mofaraheh Z, Shahsian M, Mohebi S, Tabaraee Y. The effect of marital counseling on sexual satisfaction of couples in Shiraz city. Health System Research. 2010; 6(3): 417-24.

25) Karimi A, Dadgar S, Afiat M, Rahimi N. The Effect of Sexual Health Education on Couples' Sexual Satisfaction. The Iranian Journal of Obstetrics, Gynecology and Infertility. 2013; 15(42): 23-30.

26) Rostamkhani F, Ozgoli G, Khoei EM, Jafari F, Majd HA. Effectiveness of the PLISSIT-based Counseling on sexual function of women. Journal of Shahid Beheshti School of Nursing \& Midwifery. 2012; 22(76).

27) Olsen DH, McCubbin HI, Barnes H, Larsen A, Muxen M, Wilson M. Families: What makes them work. Newbury Park: Sage. 1989.

28) Khanabadi M. Combined efficacy analysis of TA-CT on marital satisfaction. Allameh tabatabaee University. 2010.

29) Mangeli M, Gholami M, editors. Marital satisfaction and related factors in pregnant women. Proceedings The 1st Conference on Hygiene and Health. 2007.

30) Schulz MS, Cowan CP, Cowan PA. Promoting healthy beginnings: A randomized controlled trial of a preventive intervention to preserve marital quality during the transition to parenthood. J Consult Clin Psychol. 2006; 74(1): 20-31. doi: 10.1037/0022-006X.74.1.20. PMID: 16551140.

31) Zimmermann-Tansella $C$, Bertagni $P$, Siani R, Micciolo R. Marital relationships and somatic and psychological symptoms in pregnancy. Soc Sci Med. 1994; 38(4): 559-64. doi: 10.1016/02779536(94)90252-6. PMID: 8184318.

32) Baron RA, Byrne D, Branscombe NR. Social Psychology, 11/E. Aufl, Boston. 2006.

33) Rahnama P, Hidarnia A, Shokravi FA, Kazemnejad A, Oakley D, Montazeri A. Why Iranian married women use withdrawal instead of oral contraceptives? A qualitative study from Iran. BMC Public Health. 2010; 10(1): 289. doi: 10.1186/1471-2458-10-289. PMID: 20509885, PMCID: PMC2888744.

34) Jahanfar S, Molaeenezhad M. Textbook of sexual disorders. Tehran: Nashr-e-Salemi. 2001.

35) Babazadeh R, Mirzaei Najmabadi K, Masoumi Z, Raei M. Investigating Effect of Teaching on SexualActivity Changes during Pregnancy. The Iranian Journal of Obstetrics, Gynecology and Infertility. 2012; 15(12): 18-26. doi: 10.22038/ijogi.2012.5696.

36) Cooper A, Stoltenberg CD. Comparison of a sexual enhancement and a communication training program on sexual and marital satisfaction. J Couns Psychol. 1987; 34(3): 309. doi: 10.1037/0022-0167.34.3.309.

37) Nouranipour RA, Besharat MA, Yousefi E. An investigation of the correlation between sexual knowledge and attitude with marital satisfation among sarried couples inhabiting in married students dormitory at shahid Beheshti University. Conseling Research and Development. 2008; 6(24): 27-39.

38) Byers ES. Relationship satisfaction and sexual satisfaction: A longitudinal study of individuals in long term relationships. J Sex Res. 2005; 42(2): 113-8. doi: 10.1080/00224490509552264. PMID: 16123841. 